\title{
A GRATUIDADE DA JUSTIÇA PARA MENOR DE IDADE EM AÇÃO DE
} ALIMENTOS ${ }_{-2} 2$

\section{THE GRATUITOUSNESS OF JUSTICE FOR MINORS IN CHILD SUPPORT SUITS}

\section{Lucas Abreu Barroso}

Doutor em Direito pela Pontifícia Universidade Católica de São Paulo. Mestre em Direito pela Universidade Federal de Goiás. Advogado. Professor na Universidade Federal do Espírito Santo. Vitória/ES. E-mail: lab1971@gmail.com.

Sara Rodrigues Pereira Assis Graduada em Direito pela Universidade Federal do Espírito Santo. Servidora pública federal comissionada. Pósgraduanda no Complexo de Ensino Renato Saraiva. Vitória/ES. E-mail: sara.rpereira711@gmail.com.

RESUMO: Este artigo se propõe a abordar a gratuidade da justiça para menor de idade em ação de alimentos, pois a investigação científica do qual provém indicou a necessidade de adequação dos critérios para sua concessão neste tipo de demanda judicial, a fim de não se confundir a situação financeira do beneficiário (crianças e adolescentes) com a de seu/sua representante/assistente legal. Vinculado à linha crítico-metodológica, este artigo busca repensar os institutos jurídicos de maneira atual e apresentar soluções para os casos concretos, bem como, ao assumir a vertente jurídico-dogmática, discutir as proposições normativas aplicáveis com a atenção voltada para a sociedade e seus conflitos, de modo a permitir que o direito alcance efetividade social.

PALAVRAS-CHAVE: Processo civil; ação de alimentos; gratuidade da justiça;

\footnotetext{
${ }^{1}$ Artigo recebido em 17/07/2021 e aprovado em 26/10/2021.

2 Artigo vinculado ao projeto de pesquisa "O direito civil na pós-modernidade jurídica" (dgp.cnpq.br/dgp/espelhogrupo/7707825343637707).
} 
Revista Eletrônica de Direito Processual - REDP.

Rio de Janeiro. Ano 16. Volume 23. Número 1. Janeiro a Abril de 2022

Periódico Quadrimestral da Pós-Graduação Stricto Sensu em Direito Processual da UERJ

Patrono: José Carlos Barbosa Moreira (in mem.). ISSN 1982-7636. pp. 799-813

www.redp.uerj.br

representação e assistência legal; situação financeira do menor de idade.

ABSTRACT: This paper aims to address the gratuitousness of justice for minors in child support claims, as the scientific research from which it comes indicated the need to adjust the criteria for its granting in this type of lawsuit, in order not to confuse the financial situation of the beneficiary (children and adolescents) with that of their representative/legal assistant. Linked to the critical-methodological line, this paper seeks to rethink the legal institutions in an up-to-date way and present solutions to concrete cases, as well as, by assuming the legal-dogmatic aspect, discuss the applicable normative propositions with the attention focused on society and its conflicts, in order to allow the law to reach social effectiveness.

KEYWORDS: Civil procedure; child support suits; gratuitousness of justice; representation and legal assistance; financial status of minors.

\section{INTRODUÇÃO}

A sociedade contemporânea (ou contemporaneidade) é comumente denominada "pós-moderna", sendo esta expressão uma mostra de sua ruptura com a modernidade. Além de representar uma perspectiva temporal, o termo "pós" aponta para a superação do domínio da racionalização e da subjetividade, próprio do pensamento moderno 3 .

Verifica-se, pois, a transição de uma sociedade fundada no individualismo, na razão e na certeza, para uma sociedade marcada pelo pluralismo e por um elevado grau de complexidade ${ }^{4}$, de modo que as estruturas e os mecanismos típicos da modernidade já não são capazes de atender às suas exigências.

Aludir à transição verificada com o advento da contemporaneidade impõe falar da

\footnotetext{
3 AMARAL, Francisco. O direito civil na pós-modernidade. In: NAVES, Bruno Torquato de Oliveira; FIUZA, César; SÁ, Maria de Fátima Freire de (coord.). Direito civil: atualidades. Belo Horizonte: Del Rey, 2003. p. 62 e 66.

4 AMARAL, Francisco. O direito civil na pós-modernidade. In: NAVES, Bruno Torquato de Oliveira; FIUZA, César; SÁ, Maria de Fátima Freire de (coord.). Direito civil: atualidades. Belo Horizonte: Del Rey, 2003. p. $72-73$.
} 
Revista Eletrônica de Direito Processual - REDP.

Rio de Janeiro. Ano 16. Volume 23. Número 1. Janeiro a Abril de 2022

Periódico Quadrimestral da Pós-Graduação Stricto Sensu em Direito Processual da UERJ

Patrono: José Carlos Barbosa Moreira (in mem.). ISSN 1982-7636. pp. 799-813

www.redp.uerj.br

necessidade de câmbio dos modelos mentais de compreensão da realidade, que, na sociedade pós-industrial, assumem novos caracteres ${ }^{5}$. Esses traços distintivos refletiram no campo jurídico, porque enquanto o sistema buscou manter-se intacto, a realidade a ele subjacente foi sendo alterada .

Assim, não se podem ignorar os influxos da contemporaneidade sobre o direito, notadamente uma concreta mudança de sentido na disciplina jurídica das relações interpessoais. Não mais se revela adequada uma normatividade construída e sustentada a partir de um sistema autorreferente de sua abstrata racionalidade dogmática ${ }^{7}$, sob pena de o direito restar alijado da evolução da experiência social.

Verifica-se no direito a travessia de um paradigma com lastro no racionalismo, no individualismo, na subjetividade, no formalismo e na segurança jurídica (formal), para um paradigma fundado na centralidade da constituição, na personalização, no pensamento problemático e na mitigação da certeza e da segurança jurídica (formal) em favor do primado da justiça ${ }^{8}$.

Neste contexto, deve ser percebida a gratuidade da justiça para menor de idade em ação de alimentos, de forma a conduzir a decisões judiciais que permitam assegurar, a um só tempo, a aplicação das proposições normativas vigentes e a justiça no caso concreto" desde logo não sendo aceitável confundir a situação financeira do menor de idade (beneficiário) com a de seu/sua representante/assistente legal.

\section{A GRATUIDADE DA JUSTIÇA COMO INSTRUMENTO DE EFETIVIDADE DO ACESSO À JUSTIÇA}

\footnotetext{
5 AMARAL, Francisco. O direito civil na pós-modernidade. In: NAVES, Bruno Torquato de Oliveira; FIUZA, César; SÁ, Maria de Fátima Freire de (coord.). Direito civil: atualidades. Belo Horizonte: Del Rey, 2003. p. 63.

6 FACHIN, Luiz Edson. Teoria crítica do direito civil. 3. ed. Rio de Janeiro: Renovar, 2012. p. 67.

7 NEVES, A. Castanheira. Digesta: escritos acerca do direito, do pensamento jurídico, da sua metodologia e outros. Coimbra: Coimbra Editora, 2010. v. 3, p. 51.

8 AMARAL, Francisco. O direito civil na pós-modernidade. In: NAVES, Bruno Torquato de Oliveira; FIUZA, César; SÁ, Maria de Fátima Freire de (coord.). Direito civil: atualidades. Belo Horizonte: Del Rey, 2003. p. 76-77.

9 CARVALHO NETTO, Menelick de; SCOTTI, Guilherme. Os direitos fundamentais e a (in)certeza do direito: a produtividade das tensões principiológicas e a superação do sistema de regras. 2. ed. rev. e atual. Belo Horizonte: Fórum, 2020. p. 44.
} 
Revista Eletrônica de Direito Processual - REDP.

Rio de Janeiro. Ano 16. Volume 23. Número 1. Janeiro a Abril de 2022

Periódico Quadrimestral da Pós-Graduação Stricto Sensu em Direito Processual da UERJ

Patrono: José Carlos Barbosa Moreira (in mem.). ISSN 1982-7636. pp. 799-813

www.redp.uerj.br

O procedimento judicial impõe o seu (parcial) custeio àqueles que dele se utilizam, por meio de um sistema de custas e despesas processuais. Exige, em tese, o pagamento antecipado dos gastos necessários à movimentação do aparato judiciário, convertendo a existência de recursos econômicos pelo jurisdicionado em pressuposto ao acesso à justiça ${ }^{10}$. Ocorre que enquanto estabelece o pagamento de custas e despesas processuais como "pressuposto indeclinável" para se buscar a via judicial de solução de conflitos, concomitantemente priva os desprovidos de receberem a devida tutela jurisdicional ${ }^{11}$.

Entretanto, o acesso à justiça configura a "pedra de toque" das questões contemporâneas do direito processual, porquanto garantia essencial à defesa dos direitos fundamentais ${ }^{12}$. A propósito, o vigente texto constitucional tornou, ele próprio, o acesso à justiça um direito fundamental, ao prever no art. $5^{\circ}, \mathrm{XXXV}$, que "a lei não excluirá da apreciação do Poder Judiciário lesão ou ameaça a direito"13.

Com fulcro no art. 5, LXXIV, da Constituição Federal (CF) e nos arts. 98 a 102 do Código de Processo Civil (CPC), a gratuidade da justiça representa "isenção individual, incondicional e intransmissível concedida à parte" ${ }^{14}$ no que concerne ao dever de antecipar as despesas necessárias à prática dos atos processuais, sendo este benefício deferido em favor daquele que demonstrar necessidade econômica. Anote-se, no entanto, que a necessidade econômica não se confunde com um estado de miserabilidade, pois aquela se relaciona, efetivamente, com a ausência de recursos da parte para arcar com as despesas processuais decorrentes da demanda judicial almejada ${ }^{15}$.

10 ASSIS, Araken de. Processo civil brasileiro: parte geral - institutos fundamentais. 2. ed. rev. e atual. São Paulo: Revista dos Tribunais, 2016. v. 2, p. 537.

11 THEODORO JÚNIOR, Humberto. Curso de direito processual civil - teoria geral do direito processual civil, processo de conhecimento e procedimento comum. 60. ed. Rio de Janeiro: Forense, 2019. v. 1, p. 336.

12 GORON, Lívio Goellner. Acesso à justiça e gratuidade: uma leitura na perspectiva dos direitos fundamentais. Revista de Processo, São Paulo, v. 195, p. 249-277, maio 2011. Versão digital.

13 RUIZ, Ivan Aparecido; SENGIK, Kenza Borges. O acesso à justiça como direito e garantia fundamental e sua importância na constituição da República Federativa de 1988 para a tutela dos direitos da personalidade. Revista Jurídica Cesumar - Mestrado, Maringá, v. 13, n. 1, p. 209-235, jan./jun. 2013. p. 219: “[...] de maneira que se pressupõe que todos, indistintamente, possuem o direito de postular, perante os órgãos do Poder Judiciário, a tutela jurisdicional adequada e efetiva, respeitando-se, por óbvio, as garantias do devido processo legal e, principalmente, o seu consectário, o princípio do contraditório e da ampla defesa e, ainda, as normas de ordem processual aplicáveis à espécie".

14 ASSIS, Araken de. Processo civil brasileiro: parte geral - institutos fundamentais. 2. ed. rev. e atual. São Paulo: Revista dos Tribunais, 2016. v. 2, p. 539-540.

15 ASSIS, Araken de. Processo civil brasileiro: parte geral - institutos fundamentais. 2. ed. rev. e atual. São Paulo: Revista dos Tribunais, 2016. v. 2, p. 556. 
Revista Eletrônica de Direito Processual - REDP.

Rio de Janeiro. Ano 16. Volume 23. Número 1. Janeiro a Abril de 2022

Periódico Quadrimestral da Pós-Graduação Stricto Sensu em Direito Processual da UERJ

Patrono: José Carlos Barbosa Moreira (in mem.). ISSN 1982-7636. pp. 799-813

www.redp.uerj.br

Para o requerimento dos benefícios da gratuidade da justiça, basta à parte interessada declarar-se desprovida de fundos para arcar com as custas, com as despesas do processo e com o pagamento dos honorários advocatícios (art. 98, caput, do CPC e art. $1^{\circ}$, $\S 2^{\circ}$, da Lei $\left.n^{\circ} 5.478 / 1968\right)$. A esse respeito, cumpre observar que, sendo o requerimento de gratuidade da justiça formulado por pessoa natural, a declaração de hipossuficiência que a fundamenta é presumidamente verdadeira ${ }^{16}$.

Esta presunção é instituída em lei, a fim de privilegiar o acesso à justiça, já que seriam incompatíveis com esta garantia constitucional "eventuais delongas processuais antecedentes à concessão das gratuidades pelo juiz" ${ }^{17}$. Trata-se, entretanto, de presunção de veracidade iuris tantum (art. $1^{\circ}, \S 3^{\circ}$, da Lei $n^{\circ} 5.478 / 1968$ ), incumbindo à outra parte a apresentação de prova apta a infirmar a alegação de insuficiência de recursos formulada pela parte requerente ${ }^{18}$.

Assim, não se pode afastar a relevância da gratuidade da justiça e de sua adequada interpretação e aplicação, pois se está diante da garantia constitucional do acesso à justiça, a qual, apesar de sua difícil definição, aponta para duas finalidades essenciais: "primeiro, o sistema deve ser igualmente acessível a todos; segundo, ele deve produzir resultados que sejam individual e socialmente justos" ${ }^{19}$.

A essencialidade do direito a alimentos para viabilizar uma vida digna àqueles que por si mesmos não reúnem condições de satisfazer suas necessidades existenciais e a recorrência com que crianças e adolescentes precisam ingressar em juízo para pleitear alimentos impõem repensar a gratuidade da justiça no processo civil brasileiro, questionando-se o que deve ser considerado para a concessão do benefício na ação de alimentos cujo autor seja menor de idade.

\section{A GRATUIDADE DA JUSTIÇA PARA MENOR DE IDADE EM AÇÃO DE}

16 BUENO, Cassio Scarpinella. Curso sistematizado de direito processual civil. 9. ed. São Paulo: Saraiva, 2018. v. 1, p. 505.

17 DINAMARCO, Cândido Rangel. Instituições de direito processual civil. 7. ed. rev. e atual. São Paulo: Malheiros, 2017. v. 2, p. 798.

18 ASSIS, Araken de. Processo civil brasileiro: parte geral: institutos fundamentais. 2. ed. rev. e atual. São Paulo: Revista dos Tribunais, 2016. v. 2, p. 561-562.

19 CAPPELLETTI, Mauro; GARTH, Bryant. Acesso à justiça. Tradução de Ellen Gracie Northfleet. Porto Alegre: Fabris, 1988. p. 8. 
Revista Eletrônica de Direito Processual - REDP.

Rio de Janeiro. Ano 16. Volume 23. Número 1. Janeiro a Abril de 2022

Periódico Quadrimestral da Pós-Graduação Stricto Sensu em Direito Processual da UERJ

Patrono: José Carlos Barbosa Moreira (in mem.). ISSN 1982-7636. pp. 799-813

www.redp.uerj.br

\section{ALIMENTOS}

Diante da exigência de o alimentando menor de idade estar representado ou assistido para defender suas pretensões em juízo, surge o seguinte questionamento: a análise da insuficiência de recursos visando a concessão da gratuidade da justiça na ação de alimentos deve ser realizada sobre a situação financeira do alimentando menor de idade (criança ou adolescente) ou do seu representante/assistente legal, o mais das vezes sua genitora?

O entendimento que se busca sedimentar, a partir de pesquisa sobre o problema proposto, volta-se à promoção da dignidade de crianças e adolescentes por meio do acesso à justiça, de modo a suprir suas necessidades materiais e, por conseguinte, assegurar o pleno desenvolvimento de suas personalidades e potencialidades psicofísicas.

O direito a alimentos é sobremodo relevante, mormente se considerado que não se alude a um fenômeno jurídico isolado, mas que compõe um conjunto de interações que geralmente ocorre dentro de famílias em litígio ${ }^{20}$, o que exige ainda mais do direito (processual) no intuito de garantir a sua efetividade.

Contudo, é evidente o inexpressivo tratamento acerca da sequência alimentos capacidade processual - gratuidade da justiça, tanto na legislação quanto na doutrina. Nesse sentido, importa, inicialmente, identificar a parte autora na ação de alimentos. Para Cândido Rangel Dinamarco, o demandante (autor, na fase de conhecimento, ou exequente, no cumprimento de sentença) é aquele que "externa sua dupla pretensão ao Estado-juiz", a fim de que $(i)$ este preste o serviço jurisdicional, e, por meio deste serviço, (ii) realize seu interesse em alcançar dado bem da vida ${ }^{21}$. Partindo de tal compreensão, infere-se que no pleito de alimentos por crianças e adolescentes, são estes sujeitos de direito, por certo, que assumem a posição de autores da causa.

Devido à ausência da capacidade processual de crianças e adolescentes, necessário que sejam representados ou assistidos, conforme dispõe o art. 71 do CPC: “O incapaz será

20 Vide HUSNI, Alicia; RIVAS, Maria Fernanda. Familias en litigio: perspectiva psicossocial. 2. ed. atual. e ampl. Buenos Aires: Abeledo Perrot, 2013. E-book.

21 DINAMARCO, Cândido Rangel. Instituições de direito processual civil. 7. ed. rev. e atual. São Paulo: Malheiros, 2017. v. 2, p. 137. 
Revista Eletrônica de Direito Processual - REDP.

Rio de Janeiro. Ano 16. Volume 23. Número 1. Janeiro a Abril de 2022

Periódico Quadrimestral da Pós-Graduação Stricto Sensu em Direito Processual da UERJ

Patrono: José Carlos Barbosa Moreira (in mem.). ISSN 1982-7636. pp. 799-813

www.redp.uerj.br

representado ou assistido por seus pais, por tutor ou por curador, na forma da lei”.

Infere-se, pois, que o representante e o assistente não são partes. As regras de direito material e processual determinam, em específicas situações, que os direitos e os interesses de uma pessoa sejam defendidos por ou junto a outra, tal como ocorre com os incapazes, os quais são necessariamente representados ou assistidos ${ }^{22}$, e que, apesar disso, permanecem como partes no processo.

É exatamente o caso do menor de idade na ação de alimentos. Como aduz Fredie Didier Jr., "em uma ação de alimentos proposta por um filho incapaz, o pai ou mãe pode ser o seu representante processual. A parte é o incapaz; o pai ou a mãe pode ser apenas o seu representante, e não o seu substituto processual" ${ }^{23}$. Portanto, não restam dúvidas de que a parte na ação de alimentos é a criança e o adolescente, e não seu representante ou assistente legal, não havendo que se cogitar de substituição processual.

Não se sustenta, destarte, qualquer fundamentação que vincule a concessão da gratuidade da justiça à situação financeira ou ao patrimônio pessoal do representante ou assistente do alimentando (menor de idade), haja vista que se trata de benefício pessoal (art. 99, $\S 6^{\circ}$, do CPC) concedido à parte desprovida de meios para arcar com as custas, com as despesas do processo e com o pagamento dos honorários advocatícios ${ }^{24}$, e não a quem lhe complementa a capacidade processual. Com efeito, depreende-se que o benefício é concedido ao credor dos alimentos, que não possui renda ou patrimônio; do contrário, nem precisaria demandá-los judicialmente.

Como bem salientado por Maria Berenice Dias, forçoso concluir que a concessão da gratuidade da justiça independe da situação financeira ou do patrimônio pessoal do representante/assistente legal do alimentando (menor de idade), conquanto a análise das possibilidades do credor (menor de idade) é que irá respaldar os benefícios advindos da gratuidade da justiça ${ }^{25}$.

Nada obstante, a jurisprudência não é majoritariamente orientada no sentido de

22 DINAMARCO, Cândido Rangel. Instituições de direito processual civil. 7. ed. rev. e atual. São Paulo: Malheiros, 2017. v. 2, p. 138-139.

23 DIDIER JR., Fredie. Curso de direito processual civil: introdução ao direito processual civil, parte geral e processo de conhecimento. 19. ed. Salvador: Jus Podivm, 2017. v. 1, p. 401.

24 ASSIS, Araken de. Processo civil brasileiro: parte geral - institutos fundamentais. 2. ed. rev. e atual. São Paulo: Revista dos Tribunais, 2016. v. 2, p. 539.

25 DIAS, Maria Berenice. Alimentos aos bocados. São Paulo: Revista dos Tribunais, 2014. E-book. 
Revista Eletrônica de Direito Processual - REDP.

Rio de Janeiro. Ano 16. Volume 23. Número 1. Janeiro a Abril de 2022

Periódico Quadrimestral da Pós-Graduação Stricto Sensu em Direito Processual da UERJ

Patrono: José Carlos Barbosa Moreira (in mem.). ISSN 1982-7636. pp. 799-813

www.redp.uerj.br

considerar a situação financeira do alimentando (menor de idade) quando da análise da gratuidade da justiça na ação de alimentos proposta por crianças ou adolescentes. Observase com recorrente habitualidade a exigência de comprovação da insuficiência de rendimentos ou patrimônio do representante/assistente legal do credor dos alimentos (menor de idade) para o deferimento da gratuidade da justiça, chegando-se ao extremo do indeferimento do benefício simplesmente em razão do endereço residencial do alimentando (menor de idade) e seu representante/assistente legal, o mais das vezes sua genitora.

Nos termos atuais, a prática jurídica acaba por se afastar da decisão correta sobre o problema em relevo. Isso porque, considerando que o alimentando (menor de idade), em sua quase totalidade, não possui renda ou patrimônio próprio, verifica-se que ele, por não contar com os recursos necessários para assumir os custos do processo, faz jus, necessariamente, à gratuidade da justiça.

Ao atrelar a apreciação do requerimento de gratuidade da justiça à situação financeira do representante/assistente legal da criança ou adolescente que pleiteia em juízo seu direito a alimentos, privilegia-se o pagamento dos encargos econômicos oriundos da movimentação da máquina estatal para a prestação jurisdicional em detrimento da tutela de direitos que promovem a sobrevivência (minimamente) digna daqueles que não podem suprir, por si mesmos, suas mais básicas necessidades materiais.

Criou-se um ambiente de insegurança para o alimentando (menor de idade) que, nesse cenário, passa de sujeito de direito a eventual sujeito de direito ${ }^{26}$, podendo ver-se privado dos benefícios que lhe são reservados por lei, com os custos do processo sendo suportados por terceiros, ou com a desistência da propositura da demanda judicial em face da indisponibilidade de o assistente/representante legal assumi-los.

Outrossim, o exame de decisões sobre o tema evidencia a necessidade de serem explicitados, de maneira clara, os critérios adotados para o deferimento ou o indeferimento da gratuidade da justiça no cotidiano forense. Em geral, valem-se as decisões de expressões genéricas, com completa ausência de cotejo com os elementos do caso, inviabilizando a identificação dos fundamentos fático-jurídicos assumidos pelo juízo.

Ao se perquirir em que bases comumente se procede à apreciação da gratuidade da

26 FACHIN, Luiz Edson. Teoria crítica do direito civil. 3. ed. Rio de Janeiro: Renovar, 2012. p. 40. 
Revista Eletrônica de Direito Processual - REDP.

Rio de Janeiro. Ano 16. Volume 23. Número 1. Janeiro a Abril de 2022

Periódico Quadrimestral da Pós-Graduação Stricto Sensu em Direito Processual da UERJ

Patrono: José Carlos Barbosa Moreira (in mem.). ISSN 1982-7636. pp. 799-813

www.redp.uerj.br

justiça em causas em que se discute, exclusivamente, o direito a alimentos nas quais o polo ativo é ocupado por crianças ou adolescentes, não raras vezes se verifica a impossibilidade de se identificar a qual situação financeira foi vinculada a análise visando a concessão da gratuidade da justiça, se do alimentando (menor de idade) ou de seu representante/assistente legal.

Cabe indagar, assim, se tais decisões atendem, de forma satisfatória, ao comando constitucional de fundamentação das decisões (art. 93, IX), igualmente presente na lei processual civil (art. 489, II e $\S 1^{\circ}$ ). Estando-se diante do direito fundamental à motivação, tem-se que esta deve ser expressa, clara, coerente e lógica ${ }^{27}$. Conhecendo as razões de decidir, as partes estarão habilitadas para, desejando, impugnar de maneira adequada o provimento que lhes for desfavorável ${ }^{28}$.

A partir de uma fundamentação adequada é que se possibilita o reconhecimento dos critérios da decisão e sua crítica. Portanto, a inadequação dos pronunciamentos judiciais quanto ao tema revisitado, comumente verificada nas causas de alimentos propostas por alimentando (menor de idade), não reside somente em critérios que não privilegiam a efetividade do direito a alimentos, mas principalmente em sua escassa fundamentação, a qual nem sequer permite discernir quais foram os padrões decisórios que influíram no convencimento do julgador.

$\mathrm{Na}$ análise de julgados dos Tribunais de Justiça, verificou-se ser escasso o tratamento específico do tema. Entretanto, vale assinalar que os julgados que exteriorizaram os parâmetros do juízo exercido acerca da gratuidade da justiça nas causas de alimentos tendo como autor alimentando menor de idade, o fizeram seguindo a orientação proposta neste artigo.

Nesse sentido, a título de exemplo, os Agravos de Instrumento no 70010148724/RS, 70077207249/RS e 20150020183896/DF:

\section{ASSISTÊNCIA JUDICIÁRIA.}

Em se tratando de ação de alimentos proposta por um menor e um incapaz, impositiva a concessão do benefício da assistência judiciária gratuita, pois há que se atentar às condições econômicas da parte e não de

27 ASSIS, Araken de. Processo civil brasileiro: parte geral - institutos fundamentais. 2. ed. rev. e atual. São Paulo: Revista dos Tribunais, 2016. v. 1, p. 441.

28 ASSIS, Araken de. Processo civil brasileiro: parte geral - institutos fundamentais. 2. ed. rev. e atual. São Paulo: Revista dos Tribunais, 2016. v. 1, p. 444. 
Revista Eletrônica de Direito Processual - REDP.

Rio de Janeiro. Ano 16. Volume 23. Número 1. Janeiro a Abril de 2022

Periódico Quadrimestral da Pós-Graduação Stricto Sensu em Direito Processual da UERJ

Patrono: José Carlos Barbosa Moreira (in mem.). ISSN 1982-7636. pp. 799-813

www.redp.uerj.br

seu representante legal. ${ }^{29}$

AGRAVO DE INSTRUMENTO. AÇÃO DE EXECUÇÃO DE ALIMENTOS.

GRATUIDADE

JUDICIÁRIA.

RESTABELECIMENTO.

Em razão da presunção de hipossuficiência econômica (art. $1^{\circ}$, § $3^{\circ}$, da Lei de Alimentos) e do princípio da proteção integral, que recomenda seja facultado ao menor litigar gratuitamente para assegurar seus direitos, deve ser restabelecido o beneplácito da gratuidade judiciária. Agravo de instrumento provido, em monocrática. ${ }^{30}$

CIVIL. PROCESSUAL CIVIL. AGRAVO DE INSTRUMENTO. AÇÃO DE ALIMENTOS. PEDIDO DE ASSISTÊNCIA JUDICIÁRIA GRATUITA. DECLARAÇÃO DE HIPOSSUFICIÊNCIA. COMPROVAÇÃO DO ESTADO DE POBREZA. DESNECESSIDADE. MENOR DE IDADE QUE NÃO TRABALHA. AUSÊNCIA DE RENDA. LEI DE ALIMENTOS. PRESUNÇÃO DE MISERABILIDADE. POSSIBILIDADE. RECURSO PROVIDO. DECISÃO REFORMADA.

1. Consoante art. $1^{\circ}$ da Lei n. $5.478 / 68$, basta a simples afirmação do menor interessado sobre sua impossibilidade de arcar com as custas do processo sem prejuízo de sua própria subsistência e de sua família para a concessão do benefício.

2. Se o autor apresenta documentos demonstrando que é menor de idade e que não possui emprego, mostra-se desarrazoada a decisão que indefere a gratuidade judiciária com lastro na renda mensal do representante legal da parte autora.

3. Na espécie, o benefício da gratuidade de justiça é cabível pela simples demonstração nos autos de que o autor da ação de alimentos é menor e não trabalha, não tendo rendimentos para arcar com as custas processuais. Não se deve confundir a situação financeira do menor com a de sua representante legal. Ademais, sendo o requerente menor a depender de alimentos do genitor, resta evidente que faz jus ao direito vindicado.

4. Recurso conhecido e provido. Decisão reformada. ${ }^{31}$

No âmbito do Superior Tribunal de Justiça (STJ), por certo merece destaque o julgamento, no ano de 2020, do Recurso Especial nº 1807216/SP. Nele, a Terceira Turma do STJ concluiu ser indevida a vinculação da situação financeira de pessoa distinta da parte quando da análise da gratuidade da justiça. Assim, sendo a parte autora o alimentando menor de idade, não poderá ser considerada a situação financeira de seu assistente/representante legal.

29 RIO GRANDE DO SUL. Tribunal de Justiça (7ª Câmara Cível). Agravo de Instrumento no 70010148724. Relatora: Maria Berenice Dias, j. 01/11/2004. Diário de Justiça, Porto Alegre, 01 nov. 2004.

30 RIO GRANDE DO SUL. Tribunal de Justiça ( $8^{a}$ Câmara Cível). Agravo de Instrumento no 70077207249. Relator: Ricardo Moreira Lins Pastl, j. 03/04/2018. Diário de Justiça Eletrônico, Porto Alegre, 04 abr. 2018.

31 DISTRITO FEDERAL E DOS TERRITÓRIOS. Tribunal de Justiça ( $1^{\text {a }}$ Turma Cível). Agravo de Instrumento $\mathrm{n}^{\circ}$ 20150020183896. Relator: Alfeu Machado, j. 21/10/2015. Diário de Justiça Eletrônico, Brasília, 06 nov. 2015. 
Revista Eletrônica de Direito Processual - REDP.

Rio de Janeiro. Ano 16. Volume 23. Número 1. Janeiro a Abril de 2022

Periódico Quadrimestral da Pós-Graduação Stricto Sensu em Direito Processual da UERJ

Patrono: José Carlos Barbosa Moreira (in mem.). ISSN 1982-7636. pp. 799-813

www.redp.uerj.br

Se antes não se encontrava, entre os julgados do Tribunal da Cidadania, o enfrentamento específico do tema, a partir da apreciação deste Recurso Especial vislumbra-se uma possível superação do impreciso entendimento que atualmente permeia o dia a dia das varas de família país afora, pois os desacertos comumente verificados na prática forense restaram devidamente afastados pelo julgamento da Terceira Turma do STJ.

$\mathrm{Na}$ espécie, quadra registrar que o julgamento em questão se deu em controvérsia oriunda da fase de cumprimento de sentença condenatória de alimentos, na qual foram negados os benefícios da gratuidade da justiça pleiteados pelos filhos do devedor, que estavam representados por sua genitora. A negativa, em $1^{\circ}$ grau, fundou-se na ausência de comprovação da situação financeira desfavorável da genitora dos autores. Na mesma linha, o Tribunal de Justiça do Estado de São Paulo, a partir de notória confusão entre as figuras das partes e de sua representante legal, sustentou a existência de indícios acerca da possibilidade de aquelas suportarem o pagamento das custas processuais, dada a profissão exercida por sua genitora.

Afastando as motivações acima, a Ministra Nancy Andrighi, relatora do Recurso Especial, asseverou que, em função da natureza personalíssima do direito à gratuidade da justiça, os pressupostos exigidos para a sua concessão devem ser preenchidos pela parte o alimentando (menor de idade) -, e não por seu assistente/representante legal. Ademais, acertadamente, a relatora apontou ser indevida a imposição de restrições injustificadas ao direito de ação, mormente ao se considerar a natureza alimentar da obrigação em debate.

Adotando tal entendimento, concluiu a Terceira Turma do STJ que:

CIVIL. PROCESSUAL CIVIL. CUMPRIMENTO DE SENTENÇA CONDENATÓRIA DE ALIMENTOS. DIREITO AO BENEFÍCIO DA GRATUIDADE DA JUSTIÇA. NATUREZA INDIVIDUAL E PERSONALÍSSIMA. EXTENSÃO A TERCEIROS. IMPOSSIBILIDADE. EXAME DO PREENCHIMENTO DOS REQUISITOS AUTORIZADORES A PARTIR DA SITUAÇÃO ECONÔMICA DE PESSOA DISTINTA DA PARTE, COMO A REPRESENTANTE LEGAL DE MENOR. VÍNCULO forte ENTRE DIFERENTES SUJEITOS DE DIREITOS E OBRIGAÇÕES. DEPENDÊNCIA ECONÔMICA DO MENOR. AUTOMÁTICO EXAME DO DIREITO À GRATUIDADE DE TITULARIDADE DO MENOR À LUZ DA SITUAÇÃO ECONÔMICA DOS PAIS. IMPOSSIBILIDADE. CRITÉRIOS. TENSÃO ENTRE A NATUREZA 
Revista Eletrônica de Direito Processual - REDP.

Rio de Janeiro. Ano 16. Volume 23. Número 1. Janeiro a Abril de 2022

Periódico Quadrimestral da Pós-Graduação Stricto Sensu em Direito Processual da UERJ

Patrono: José Carlos Barbosa Moreira (in mem.). ISSN 1982-7636. pp. 799-813

www.redp.uerj.br

PERSONALÍSSIMA DO DIREITO E INCAPACIDADE ECONÔMICA DO MENOR. PREVALÊNCIA DA REGRA DO ART. $99, \S 3^{\circ}$, DO NOVO CPC. ACENTUADA PRESUNÇÃO DE INSUFICIÊNCIA DO MENOR. CONTROLE JURISDICIONAL POSTERIOR. POSSIBILIDADE. PRESERVAÇÃO DO ACESSO À JUSTIÇA E CONTRADITÓRIO. RELEVÂNCIA DO DIREITO MATERIAL. ALIMENTOS. IMPRESCINDIBILIDADE DA SATISFAÇÃO DA DÍVIDA. RISCO GRAVE E IMINENTE AOS CREDORES MENORES. IMPOSSIBILIDADE DE RESTRIÇÃO INJUSTIFICADA AO EXERCÍCIO DO DIREITO DE AÇÃO. REPRESENTANTE LEGAL QUE EXERCE ATIVIDADE PROFISSIONAL. VALOR DA OBRIGAÇÃO ALIMENTAR. IRRELEVÂNCIA.

1- Recurso especial interposto em 18/05/2018 e atribuído à Relatora em 13/02/2019.

2- O propósito recursal é definir se, em ação judicial que versa sobre alimentos ajuizada por menor, é admissível que a concessão da gratuidade de justiça esteja condicionada a demonstração de insuficiência de recursos de seu representante legal.

3- O direito ao benefício da gratuidade de justiça possui natureza individual e personalíssima, não podendo ser automaticamente estendido a quem não preencha os pressupostos legais para a sua concessão e, por idêntica razão, não se pode exigir que os pressupostos legais que autorizam a concessão do benefício sejam preenchidos por pessoa distinta da parte, como o seu representante legal.

4- Em se tratando de menores representados pelos seus pais, haverá sempre um forte vínculo entre a situação desses dois diferentes sujeitos de direitos e obrigações, sobretudo em razão da incapacidade civil e econômica do próprio menor, o que não significa dizer, todavia, que se deva automaticamente examinar o direito à gratuidade a que poderia fazer jus o menor à luz da situação financeira de seus pais.

5- A interpretação que melhor equaliza a tensão entre a natureza personalíssima do direito à gratuidade e a notória incapacidade econômica do menor consiste em aplicar, inicialmente, a regra do art. 99, $\S 3^{\circ}$, do novo CPC, deferindo-se o benefício ao menor em razão da presunção de sua insuficiência de recursos, ressalvada a possibilidade de o réu demonstrar, com base no art. $99, \S 2^{\circ}$, do novo CPC, a posteriori, a ausência dos pressupostos legais que justificam a gratuidade, o que privilegia, a um só tempo, os princípios da inafastabilidade da jurisdição e do contraditório.

6- É igualmente imprescindível que se considere a natureza do direito material que é objeto da ação em que se pleiteia a gratuidade da justiça e, nesse contexto, não há dúvida de que não pode existir restrição injustificada ao exercício do direito de ação em que se busque o adimplemento de obrigação de natureza alimentar.

7- $\mathrm{O}$ fato de o representante legal das partes possuir atividade remunerada e o elevado valor da obrigação alimentar que é objeto da execução não podem, por si só, servir de empeço à concessão da gratuidade de justiça aos menores credores dos alimentos. 
Revista Eletrônica de Direito Processual - REDP.

Rio de Janeiro. Ano 16. Volume 23. Número 1. Janeiro a Abril de 2022

Periódico Quadrimestral da Pós-Graduação Stricto Sensu em Direito Processual da UERJ

Patrono: José Carlos Barbosa Moreira (in mem.). ISSN 1982-7636. pp. 799-813

www.redp.uerj.br

8- Recurso especial conhecido e provido ${ }^{32}$.

Os dados colhidos pelo estudo que se encerra e seu cotejo com os enunciados normativos constitucionais e infraconstitucionais sobre o tema, assim também com a bibliografia especializada, permitem afirmar ser inadiável a necessidade de que a prática forense, ao analisar a insuficiência de recursos e a correlata declaração de hipossuficiência, visando a concessão da gratuidade da justiça ao alimentando menor de idade, efetivamente o faça em relação à situação financeira da criança ou adolescente que pleiteia alimentos.

Nem por isso se propõe aqui uma prestação jurisdicional gratuita a todas as crianças e/ou adolescentes, esvaziando o sentido da gratuidade de justiça, mas que sua correta e adequada concessão evite que os custos do processo obstaculizem o exercício jurisdicional dos direitos $^{33}$, em especial o direito a alimentos, essencial à promoção de uma vida (minimamente) digna.

\section{CONSIDERAÇÕES FINAIS}

Com alicerce em uma interpretação crítica e constitucionalizada das categorias jurídicas envolvidas, este artigo se dispôs a repensá-los de maneira atual, a apresentar soluções para os casos concretos e a extrair sentidos do direito material e processual a partir da pessoa humana e dos valores democráticos, de modo a permitir que o direito alcance efetividade social.

Sob essa ótica, foram revisitados o direito a alimentos, o acesso à justiça, a capacidade processual, o direito fundamental à motivação e a gratuidade da justiça no ordenamento jurídico brasileiro, com a atenção voltada para a família e seus conflitos, concluindo-se pelo papel primordial do processo judicial na tutela da verba alimentar, a fim de garantir uma existência (minimamente) digna do alimentando (menor de idade).

A partir da prática forense urgem alguns inadiáveis ajustes. Primeiro, por terem sido encontradas muitas decisões cuja fundamentação é escassa relativamente ao requerimento de gratuidade da justiça, o que inviabiliza: $(i)$ o reconhecimento dos critérios

32 BRASIL. Superior Tribunal de Justiça (3. Turma). Recurso Especial n ${ }^{\circ}$ 1807216/SP. Relatora: Ministra Nancy Andrighi, j. 04/02/2020. Diário de Justiça Eletrônico, Brasília, 06 fev. 2020.

33 BUENO, Cassio Scarpinella. Curso sistematizado de direito processual civil. 9. ed. São Paulo: Saraiva, 2018. v. 1, p. 151. 
Revista Eletrônica de Direito Processual - REDP.

Rio de Janeiro. Ano 16. Volume 23. Número 1. Janeiro a Abril de 2022

Periódico Quadrimestral da Pós-Graduação Stricto Sensu em Direito Processual da UERJ

Patrono: José Carlos Barbosa Moreira (in mem.). ISSN 1982-7636. pp. 799-813

www.redp.uerj.br

que influíram na construção do pronunciamento judicial, e (ii) a impugnação de seus termos. Segundo, por ainda se mostrarem uma realidade no foro judicial decisões que vinculam a concessão da gratuidade da justiça aos recursos financeiros e ao patrimônio do representante/assistente legal do alimentando (menor de idade).

A concessão da gratuidade da justiça em causas de alimentos envolvendo crianças e/ou adolescentes constitui instrumento de efetividade do acesso à justiça, pelo que se encerra concluindo pela necessária adequação dos padrões decisórios atuais à situação financeira do alimentando (menor de idade) que pleiteia a verba alimentar, buscando averiguar se ele conta com recursos para, por si mesmo, arcar com as custas, as despesas processuais e os honorários advocatícios, o que, via de regra, não se constata.

\section{REFERÊNCIAS:}

AMARAL, Francisco. O direito civil na pós-modernidade. In: NAVES, Bruno Torquato de Oliveira; FIUZA, César; SÁ, Maria de Fátima Freire de (coord.). Direito civil: atualidades. Belo Horizonte: Del Rey, 2003. p. 61-77.

ASSIS, Araken de. Processo civil brasileiro: parte geral - institutos fundamentais. 2. ed. rev. e atual. São Paulo: Revista dos Tribunais, 2016. 2 v.

BRASIL. Superior Tribunal de Justiça (3. Turma). Recurso Especial $n^{\circ}$ 1807216/SP. Relatora: Ministra Nancy Andrighi, j. 04/02/2020. Diário de Justiça Eletrônico, Brasília, 06 fev. 2020.

BUENO, Cassio Scarpinella. Curso sistematizado de direito processual civil. 9. ed. São Paulo: Saraiva, 2018. v. 1.

CAPPELlETTI, Mauro; GARTH, Bryant. Acesso à justiça. Tradução de Ellen Gracie Northfleet. Porto Alegre: Fabris, 1988.

CARVALHO NETTO, Menelick de; SCOTTI, Guilherme. Os direitos fundamentais e a (in)certeza do direito: a produtividade das tensões principiológicas e a superação do sistema de regras. 2. ed. rev. e atual. Belo Horizonte: Fórum, 2020.

DIAS, Maria Berenice. Alimentos aos bocados. São Paulo: Revista dos Tribunais, 2014. Ebook.

DIDIER JR., Fredie. Curso de direito processual civil: introdução ao direito processual 
Revista Eletrônica de Direito Processual - REDP.

Rio de Janeiro. Ano 16. Volume 23. Número 1. Janeiro a Abril de 2022

Periódico Quadrimestral da Pós-Graduação Stricto Sensu em Direito Processual da UERJ

Patrono: José Carlos Barbosa Moreira (in mem.). ISSN 1982-7636. pp. 799-813

www.redp.uerj.br

civil, parte geral e processo de conhecimento. 19. ed. Salvador: Jus Podivm, 2017. v. 1.

DINAMARCO, Cândido Rangel. Instituições de direito processual civil. 7. ed. rev. e atual. São Paulo: Malheiros, 2017. v. 2.

DISTRITO FEDERAL E DOS TERRITÓRIOS. Tribunal de Justiça (1 ${ }^{\mathrm{a}}$ Turma Cível). Agravo de Instrumento $\mathrm{n}^{\mathrm{o}}$ 20150020183896. Relator: Alfeu Machado, j. 21/10/2015. Diário de Justiça Eletrônico, Brasília, 06 nov. 2015.

FACHIN, Luiz Edson. Teoria crítica do direito civil. 3. ed. Rio de Janeiro: Renovar, 2012.

GORON, Lívio Goellner. Acesso à justiça e gratuidade: uma leitura na perspectiva dos direitos fundamentais. Revista de Processo, São Paulo, v. 195, p. 249-277, maio 2011. Versão digital.

HUSNI, Alicia; RIVAS, Maria Fernanda. Familias en litigio: perspectiva psicossocial. 2. ed. atual. e ampl. Buenos Aires: Abeledo Perrot, 2013. E-book.

NEVES, A. Castanheira. Digesta: escritos acerca do direito, do pensamento jurídico, da sua metodologia e outros. Coimbra: Coimbra Editora, 2010. v. 3.

RIO GRANDE DO SUL. Tribunal de Justiça (7 Câmara Cível). Agravo de Instrumento no 70010148724. Relatora: Maria Berenice Dias, j. 01/11/2004. Diário de Justiça, Porto Alegre, 01 nov. 2004.

RIO GRANDE DO SUL. Tribunal de Justiça ( $8^{a}$ Câmara Cível). Agravo de Instrumento no 70077207249. Relator: Ricardo Moreira Lins Pastl, j. 03/04/2018. Diário de Justiça Eletrônico, Porto Alegre, 04 abr. 2018.

RUIZ, Ivan Aparecido; SENGIK, Kenza Borges. O acesso à justiça como direito e garantia fundamental e sua importância na constituição da República Federativa de 1988 para a tutela dos direitos da personalidade. Revista Jurídica Cesumar - Mestrado, Maringá, v. 13, n. 1, p. 209-235, jan./jun. 2013.

THEODORO JÚNIOR, Humberto. Curso de direito processual civil: teoria geral do direito processual civil, processo de conhecimento e procedimento comum. 60. ed. Rio de Janeiro: Forense, 2019. v. 1. 